\title{
Application of Traditional Calligraphy in Modern Graphic Design
}

\author{
$\mathrm{Pu}$ Zhang \\ Huanghe Science and Technology College \\ Zhengzhou, China
}

\begin{abstract}
By wide application of traditional calligraphy, modern graphic design with a unique art form has performed the cultural connotation and distinct charm of traditional calligraphy, which is a kind of innovation. Calligraphy is an artistic activity that takes aesthetics as the starting point, directly or indirectly expressing calligraphers' aesthetic ideal and sentiment. The art elements of traditional calligraphy have played an irreplaceable role in various fields of graphic design. As the significant visual elements in graphic design, graphic and text act as a part of decoration and information transformation.
\end{abstract}

Keywords-Calligraphy; modern; graphic design; application

\section{INTRODUCTION}

Nowadays, the art elements of traditional calligraphy have been extensively applied to various designs. Since China is of a long history and civilization, various artistic forms are created by ancestors and calligraphy is one of them. "As a unique traditional art form of Chinese nation, calligraphic art mainly manifests people's disposition, character and sentiment by Hanzi's beauty of brush, ink, stippling, structure, transportation times, rules and so on to reach the realm of aesthetics." To well use the elements of traditional calligraphy can enormously enhance the taste and connotation of graphic design works. With the society's development and computer's universality, calligraphic art, as the critical elements in Chinese traditional art, has highlighted its significant value and cultural connotation in graphic design art. The works applying calligraphic art as design elements have related to fields as designs in advertising, packaging, book, poster, logo, etc. Especially in recent years, such traditional calligraphy fonts as semi-cursive script, regular script, clerical script, etc. have appeared in computer word stock. These outstanding word stocks have provided more design resources for graphic designers.

In 2008, Beijing Olympic Games has especially pushed calligraphic art to the world. In the opening ceremony of Beijing Olympic Games, Chinese calligraphy, traditional Chinese painting, Peking Opera, Tai Ji, silk, Four Great Inventions, etc. have fully displayed the artistic charm of Chinese traditional culture. With Chinese painting and calligraphy axis as the main line, the opening ceremony has showed the whole development process of Chinese civilization "Fig. 1". And the guide card of every country's representative team is written in calligraphy. As an artistic category, calligraphy whose decorativeness, artistry and aestheticism etc. all contribute to the development and application of graphic design holds an indispensible position in graphic design. In traditional culture, calligraphy is most exposed, which exists extensively in the advertisement and tablet when walking in streets. The "People's Bank of China" on RMB paper currency is written in clerical script. The logo of Beijing Olympic Games is the perfect combination of China Seal and traditional calligraphy, and the logo of bidding for Olympics and that of Shanghai World Expo in 2010 present the widespread application of calligraphic art. The charm of traditional calligraphy art is manifested in various fields such as tea packaging, alcohol packaging, book name, brand name, movie poster, etc.

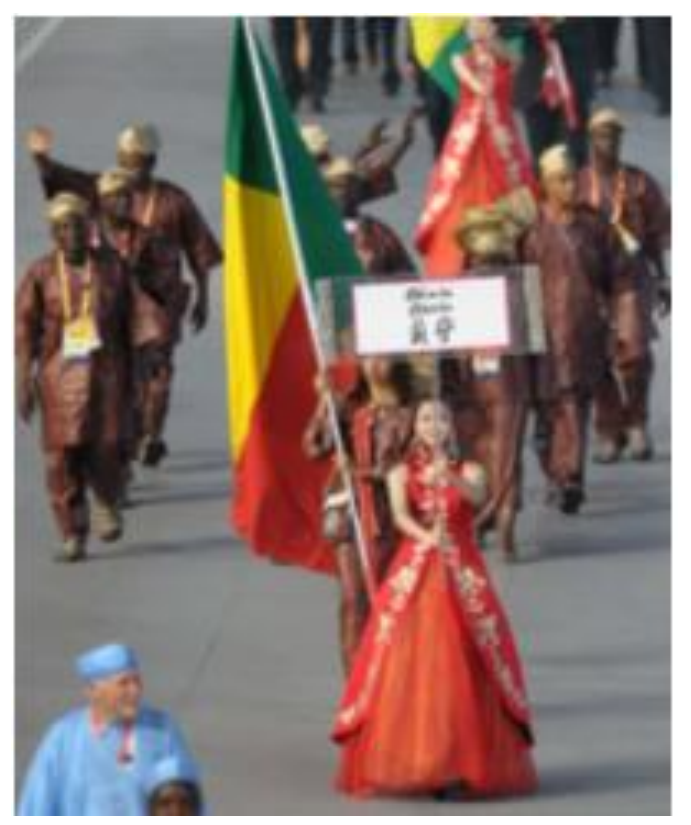

Fig. 1. Olympic Guide Card

\section{The CONSTITUENT ElEMENTS OF TRADITIONAL CALLIGRAPHY IN GRAPHIC DESIGN}

The artistic elements of traditional calligraphy are displaying their indispensible functions in various fields of graphic design. Calligraphic art is mainly manifested by such elements as brushwork, structure and rules. The characters written by writing brush have a stroke of rich lines with countless changes and have the aesthetic sentiment and artistic 
philosophy of art modeling, which is what we called brush style. As an important component of calligraphic art, brush work can embody the changes of graphic design work better like poster design in Kan Tai-keung and Wang Xu. While writing calligraphy, attach attention to both brush style and structure. Structure, also called socket, inter-frame structure or guitar body, is formed by point collocation which denotes the arrangement of dot-and-dash and layout of shape. To make the stroke of characters being suitable, appropriate and even, its guitar body is very necessary. Meanwhile, brush style makes various types of structure and beautifies these types. Therefore, in graphic design, brush style should be used flexibly and adapted reasonably for creating excellent graphic design works. For instance, the ZhuXi Bangshu Qianziwen of Lu Jingren the famous book design master in China, decomposes the structure in calligraphy and uses point, slash and back slash as book I, II and III.

As one constituent element of calligraphy, rules are equally important in graphic design. "Rules are another mark of calligraphic art's maturity. Rules denote the methods in arranging the whole work which includes the correspondence and care of characters and lines, etc. As the constituent relations of calligraphic works' visual space, rules are the orders and rules of processing calligraphic works' visual space relations." Being one significant part of calligraphic art, rules can manifest itself in the composition of graphic design works, the rationality of arrangement, etc.

\section{THE APPLICATION OF TRADITIONAL CALLIGRAPHY TO GRAPHIC DESIGN}

As the important visual elements in graphic design, graphic and text play a role of decoration and information transformation. The traditional graphic design usually adopts computer art words, which have some limitations. While graphic design should innovate and develop, it can draw inspiration from traditional calligraphy. The basic elements such as ink element, point-line structure, rules and blank of traditional calligraphy can be used by designers to draw latest information. Flexibly applying artistic elements of traditional calligraphy can not only enhance the visual effect but also add the cultural connotation of graphic design. The so-called cultural connotation is to inject the essence of traditional culture to graphic design so as to improve the national features of Chinese graphic design works. For instance, in the logo of Beijing Olympic Games in 2008 "Fig. 2", that of Henan University "Fig. 3", etc. all adopt the artistic form of seal script. Clerical script is the simplified form of seal script with a flat, neat and exquisite guitar body. In ancient times, clerical script mainly is applied to silk painting, lacquer, portrait and uranium mirror, while is used as company or enterprise's names and so on "Fig. 4". With a mannered stroke, well-knit structure, a steady center and practicability, regular script is mainly used in writing and can embody aesthetic sentiment and cultural accomplishment of the writer. Regular script is suitable for using in industrial products, Food, drink, medicament etc; as the best font which combining practicability and artistry for its convenience and fluent stroke, semi-cursive script is mainly applied to logo, poster "Fig. 5", "Fig. 6", alcohol and tobacco packaging, etc. Although having simple structure, unbroken stroke and being difficult to indentify, cursive script can manifest its artistry, appreciation and aesthetic value. Cursive script is mostly used in advertising design, wine packaging, book cover design and so on. Using traditional calligraphy in graphic design can express strong artistry in logo design, embody nobleness and elegance of goods in packaging design, improve classicism and rich connotation of books in book design, and add color in poster design. A large number of facts indicate that flexibly using traditional calligraphy in graphic design and combining tradition and contemporary can enrich our design and make us feel the rich implication and spiritual connotation of graphic design. For example, the logo designs of Mengniu Dairy, the packaging design of moon cake box, etc. "Fig. 7", "Fig. 8".

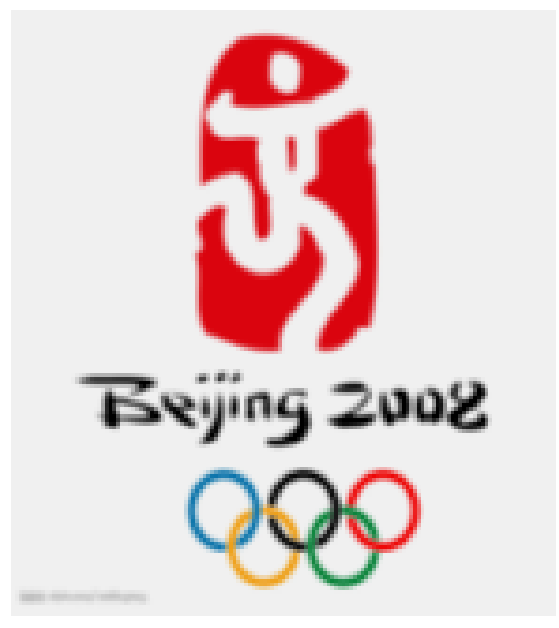

Fig. 2. Logo of Olympic Games

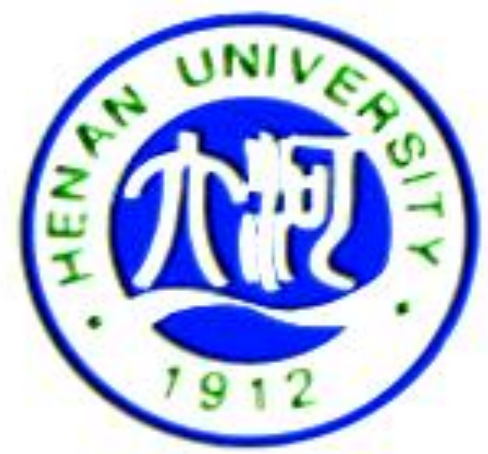

Fig. 3. Logo of Henan University

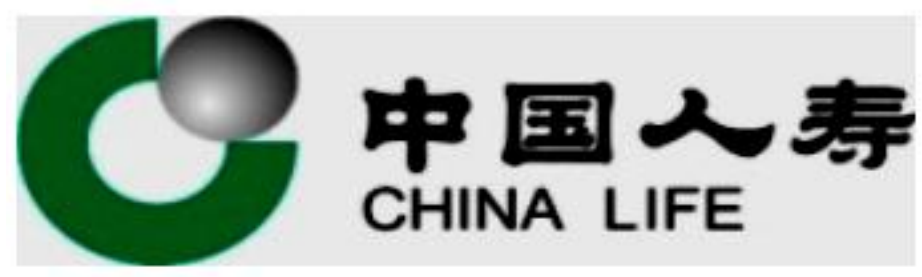

Fig. 4. Logo of China Life 


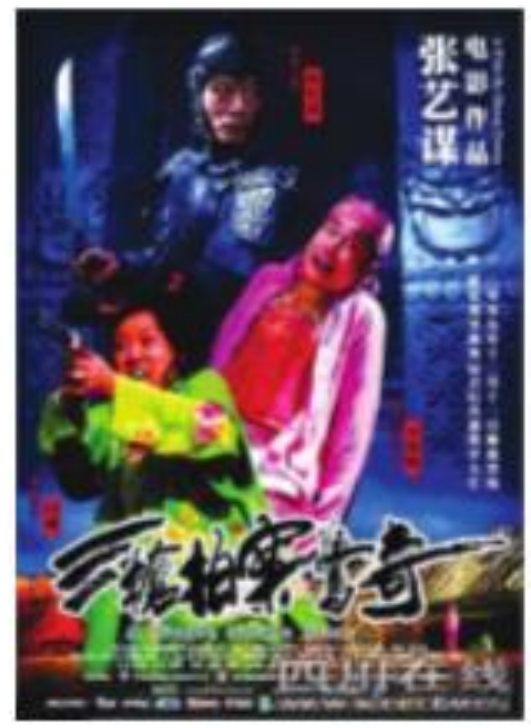

Fig. 5. Movie Poster Design

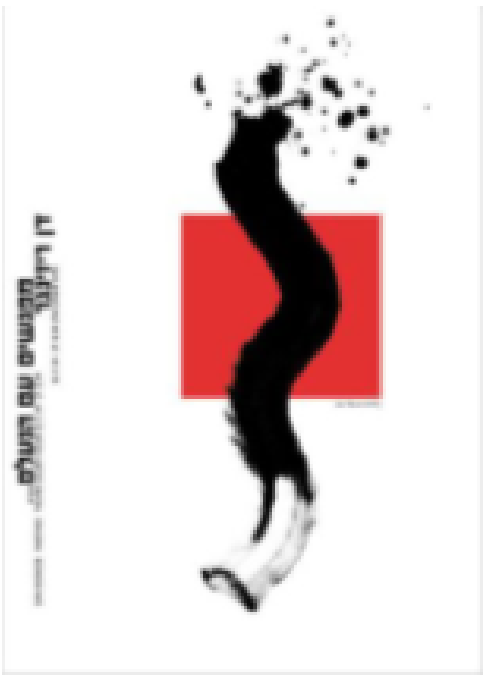

Fig. 6. Foreign Creative Poster Design

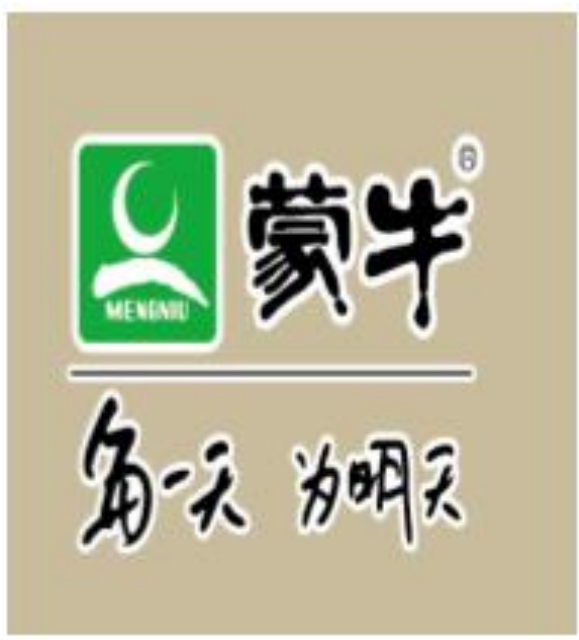

Fig. 7. Logo Design of Mengniu Dairy

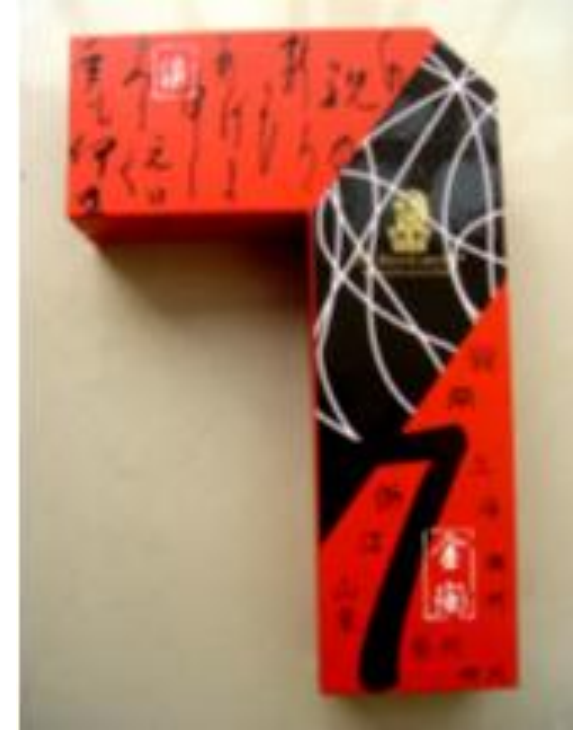

Fig. 8. Packaging Design of Moon Cake Box

\section{HOW TO PERFORM AND REFER to TRAditional CALligraphy IN GRAPHIC DESIGN}

Graphic design cannot leave alone text and while calligraphy is also the main performance of Chinese character. As the traditional Chinese art, calligraphy is the unity of practicality and artistry. Blending traditional calligraphy into graphic design can not only transform information better and satisfy audience's visual psychological requirements but also reflect the cultural connotation of graphic design. Blending calligraphy into graphic design is a way and tool of design creation. Graphic design and traditional calligraphy are both art, and a lot of commonness, similarity and internal relations are between them. Modern people with complex aesthetic views easily accept and master traditional calligraphic art so as to understand the traditional culture better. And blending traditional culture inherited from ancestors into graphic design will increase the cultural connotation of design works and enhance works' expressive force and vitality.

Borrowing the artistic elements of traditional calligraphy perform creatively for graphic design. It doesn't denote a completely copy but indicates using artistic elements of traditional calligraphy to improve the graphic design level. From the modern view, calligraphy in graphic design is a design already. In function, it protects calligraphic works and prolongs its life; in aesthetics, it serves as significant ornament and beautification. In fact, people can totally take it as one form of packaging design. Painting and calligraphy decoration art developing with the developing needs of traditional painting art has been a natural and independent subject in graphic design discipline.

The characters in traditional calligraphy can be assemble or split so as to create new design configuration. For instance, express design through the shade, wet-dry and withered-coke of ink. In his poster works, Kan Tai-keung applied the ink of calligraphy to express. By combining traditional ink with modern design, his works has most ethnic characteristics and 
embodies profound cultural connotations. Kan Tai-keung advocates a deeply understanding of Chinese traditional culture and combining spirit of traditional culture and Western advanced design concepts based on this understanding. The logo of Bank of China is his classic work of blending Eastern and Western design concepts "Fig. 9".
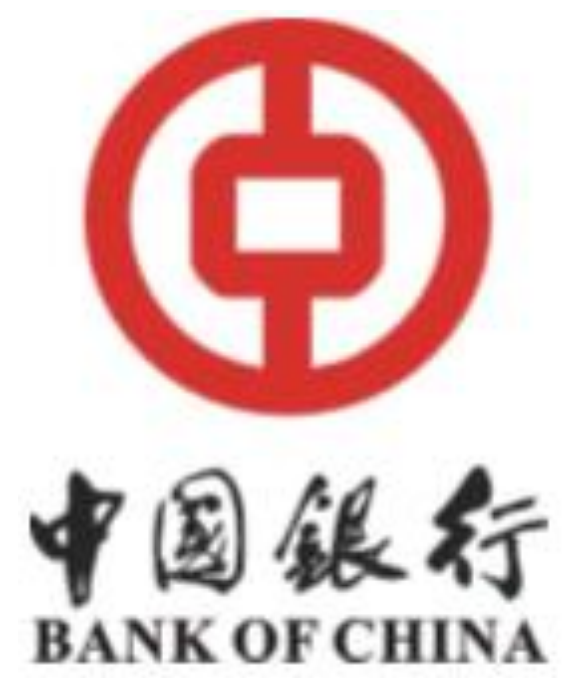

Fig. 9. Logo of Bank of China

\section{CONCLUSION}

With the continuous improvement of society, renewal of people's aesthetic concepts, and more colorful and diversified of various aesthetic requirements, calligraphy and design have developed toward pluralism and multi polarization. The perfect unity of various opposed aesthetic elements namely art's independence and commonness with traditional culture decides the skill difficulties of art and necessary ability for mastering this art. The understanding and mastering of profound Chinese traditional culture are necessary accomplishment of designers. In graphic design, many traditional calligraphy elements besides ink such as its style beauty can be referred to. Style is the general characteristics in content and form of calligraphers' works and the high generalization of art's aesthetics. From content, form and spiritual connotation, calligraphy has vast commonness with graphic design. Therefore, the graphic design shall embody certain design style and high generalization for art. Calligraphy and design shall perform their epoch beauty in a higher category.

\section{REFERENCES}

[1] Kan Tai-keung. Kan Tai-keung Design Award [M]. Beijing: China Youth Publishing Group,2009

[2] E. H. Gombrich. The Sense of Order [M]. Hangzhou: Zhejiang Photographic Press, 1978: 341

[3] Peng Jixiang. Introduction to Art [M]. Beijing: Beijing University Press, 1994 